\title{
IDENTIFICATION OF FULLERENES IN IRON-CARBON ALLOYS STRUCTURE
}

\section{ExTENDEd Abstract:}

Steels of various purposes are used in the construction industry, for example, as the reinforcement material in reinforced concrete structures. In the oil and gas industry, steel structures are used for storage and transportation of explosive toxic media. In this case the catastrophic damages might take place, that points at insufficiently deep knowledge about the processes running in structural materials when load is applied. Recent studies show that many properties of steel are set at the nanoscale level during crystallization from the molten metal and thermal treatment. To detect and identify fullerenes $\mathrm{C60}$ and $\mathrm{C70}$, which are independent nanoscale objects in steel structure, by various methods requires studying of how these objects influence on formation of steel properties. Iron atoms can serve as a catalyst and, interacting with large aromatic structures or fragments of the graphite planes, they form voluminous fullerene-type structures. The inverse phenomenon, i.e. influence of the formed nanoscale objects on structuring of the iron atoms, is also possible, as fullerene size is comparable with the size of the stable nucleus of the iron crystalline phase. The article discusses the issue of mechanisms of fullerenes formation in steels and cast irons. The most complicated issue in the study is the fullerenes identification by spectral methods as the quantity of released molecules is small. In order to increase the sensitivity of the fullerenes IR-spectrometry method, potassium bromide has been proposed to use. Dried and reduced sediment obtained as a result of dissolving iron matrix in steels is mixed with potassium bromide, the mixture becomes bright-orange. This fact points to presence of bromic fullerenes and to presence of fullerenes in the studied specimens. It is shown that the offered specimen preparation algorithm significantly increases sensitivity of the method.

Key words: carbon, fullerenes, steels, IR spectrometry, potassium bromide, hydrofluoric acid. 
MACHINE-REAdABLE INFORMATION ON CC-LICENSES (HTML-CODE) IN METADATA OF THE PAPER

$<$ a rel="license" href="http://creativecommons.org/licenses/by/4.0/" ><img alt="Creative Commons License" style="borderwidth:0" src="https://i.creativecommons.org/l/by/4.0/88x31.png" $/></ \mathrm{a}><$ br $/><$ span xmlns:dct="http://purl.org/dc/ terms/" href="http://purl.org/dc/dcmitype/Text" property="dct:title" rel="dct:type">Identification of fullerenes in ironcarbon alloys structure. $</$ span $>$ by $<$ a xmlns:cc="http://creativecommons.org/ns\#" href="Nanotehnologii v stroitel'stve = Nanotechnologies in Construction. 2017, Vol. 9, no. 6, pp. 151-163. DOI: dx.doi.org/10.15828/2075-8545-2017-9-6-151-163." property="cc:attributionName" rel="cc:attributionURL" $>$ Kuzeev I.R. $</ \mathrm{a}>$ is licensed under a $<$ a rel="license" href="http:// creativecommons.org/licenses/by/4.0/" $>$ Creative Commons Attribution 4.0 International License $</ \mathrm{a}>$. $<$ br $/>$ Based on a work at $<$ a xmlns:dct="http://purl.org/dc/terms/" href=" http://nanobuild.ru/en_EN/nanobuild-6-2017/" rel="dct:source" $>$

http://nanobuild.ru/en_EN/nanobuild-6-2017/</a $>$. $<$ br $/>$ Permissions beyond the scope of this license may be available at $<$ a xmlns:cc="http://creativecommons.org/ns\#" href="kuzeev2002@mail.ru" rel="cc:morePermissions" > kuzeev2002@mail. $\mathrm{ru}</ \mathrm{a}>$.

\section{References:}

1. Vlasov V.A. Inventions in the field of nanotechnologies provide improvement of strength and service life of structures made of metal, composite polymer and metal-polymer materials Nanotehnologii v stroitel'stve $=$ Nanotechnologies in Construction. 2014, Vol.6, no. 1. pp. 68-90 (In Russian).

2. Vlasov V.A. Inventions in the field of nanotechnologies significantly improve operational properties off concrete, polymers, metals and other materials Nanotehnologii v stroitel'stve = Nanotechnologies in Construction. 2014, Vol.6, no. 3, pp. 77-95. (In Russian).

3. Kondakov A.I., Mikhaleva Z.A., Tkachev A.G., Popov A.I., Gorsky S.Yu. Modification of construction composite matrix by functionalized carbon nanotubes Nanotehnologii v stroitel'stve $=$ Nanotechnologies in Construction. 2014, Vol. 6, no. 4, pp. 31-44. (In Russian).

4. Zakirnichnaya M.M., Kuzeev I.R., Tkachenko O.I. Obrazovanie fullerenov v processe diffuzii ugleroda $v$ strukturu stali [Fullerenes formation in the process of carbon diffusion to the steel structure]. Izvestija vysshih uchebnyh zavedenij. Neft' i gaz. [News of higher educational institutions. Oil and gas]. 2012. № 2 . p. 112-119. (In Russian).

5. Guliaev A.P. Metallovedenie [Extractive metallurgy]. Moscow, Metallurgija [Metallurgy], 1986. 544 p. (In Russian).

6. Gubenko S.I. K voprosu o sinteze almaza [To the issue of diamond synthesis]. Materialovedenie i termicheskaja obrabotka metallov [Materials study and thermal treatment of metals]. 1994. № 3. p. 37. (In Russian). 
7. Zhukov A.A., Snezhnoy R.L., Davydov S.V. Ob obrazovanii kompaktnogo grafita v chugune [On formation of compact graphite in cast iron]. Materialovedenie i termicheskaja obrabotka metallov [Materials study and thermal treatment of metals]. 1981. № 9. p. 21. (In Russian).

8. Kimstach G.M., Utaev A.A., Molodtsova T.S. Kimstach G.M. Ob obrazovanii karbina $\mathrm{v} \mathrm{Fe}-\mathrm{C}$ splavah [On formation of carbyne in $\mathrm{Fe}-\mathrm{C}$ alloys]. Materialovedenie i termicheskaja obrabotka metallov [Materials study and thermal treatment of metals]. 1988. № 4. p. 9-12. (In Russian).

9. Kimstach G.M., Utaev A.A., Molodtsova T.S. O sushhestvovanii karbina v strukture austenitnogo chuguna [On presence of carbyne in austenitic cast iron structure]. Materialovedenie i termicheskaja obrabotka metallov [Materials study and thermal treatment of metals]. 1991. № 2. p. 17-18. (In Russian).

10. Zhukov A.A. O formah sushhestvovanija ugleroda v chugunah [On forms of carbon existence in cast irons]. Materialovedenie i termicheskaja obrabotka metallov [Materials study and thermal treatment of metals]. 1992. № 11. p. 34. (In Russian).

11. Zhukov A.A., Snezhnoy R.L., Girshovitch N.G. Soviet research work on the liquid state on cast iron. AFS International Cast Metals Journal. 1976. № 1. p. 11-16.

12. Zhukov A.A., Ramachandra Rao P. New findings in carbon chemistry and their relation to cast iron. Indian Foundry Journal. 1994. № 6. p. 13-18.

13. Gvetadze R.G., Khidasheli N.Z., Cherny V.G., Gogesashvili G.N., Svistunova Z.V. Osobennosti formirovanija struktury vysokoprochnyh deformiruemyh chugunov [Peculiarities of high-strength deformable cast irons formation]. Litejnoe proizvodstvo [Foundry]. 1990. № 3. p. 708. (In Russian).

14. Lipson $H$. The crystal structure of cementite $\mathrm{Fe}_{2} \mathrm{C} / \mathrm{H}$. Lipson, N.J. Petch // Iron and Steel Institute. Vol. 142. № 1. p. 95-106. (In Russian).

15. Gavrilyuk V.G. Raspredelenie ugleroda v stali [Distribution of carbon in steel]. Kyiv, Naukova dumka, 1987. 207 p. (In Russian).

16. Rakhmanov N.Ya., Sirenko A.F., Balarev S.A. Teplovoe rasshirenie cementita zajevtektoidnogo zhelezouglerodistogo splava [Thermal expansion of hypereutectoid iron-carbon alloy cementite]. Materials study and thermal treatment of metals. 1997. № 1. p. 6-11. (In Russian).

17. Arzamasov B.N. Materialovedenie [Materials study]. Moscow, Mashinostroenie [Mechanical engineering], 1986. 394 p. (In Russian).

18. Zakirnichnaya M.M. Obrazovanie fullerenov v uglerodistyh stalyah i chugunah pri kristallizacii i termicheskih vozdejstviyah [Fullerene formation of in carbon steels and cast irons during crystallization and thermal influences]. Ufa, Publishing house «Gilem», 2002. 180 p. (In Russian). 
19. Kuzeev I.R., Popova S.V., Savicheva Yu.N. Issledovanie uglerodnyh form v zhelezouglerodistyh splavah [Study of carbon molds in iron-carbon alloys]. Geologija. Izvestija Otdelenija nauk o Zemle i prirodnyh resursah AN RB [Geology. News of Department of Earth sciences and natural resources Academy of Sciences of the Republic of Bashkortostan]. 2009. № 14. p. 135-136. (In Russian).

20. Domrachev G.A., Lazarev A.I., Kaverin B.S., Egorochkin A.N., Obyedkov A.M., Domracheva E.G., Domracheva L.G., Marki G.V., Huipe Nava E., Sorokin A.A., Suvorova O.N., Karnatsevich V.L., Kirillov A.I., Zakurazhnov A.A. Rol' ugleroda i metalla v samoorganizacii sistemy zhelezo - uglerod pri razlichnom soderzhanii komponentov [Role of carbon and metal in self-ogranization of iron-carbon system with various content of components]. Fizika tverdogo tela [Physics of the Solid State]. 2004. V. 46. Issue 10. p. 1901-1915. (In Russian).

21. Bekhterev A.N. Spektroskopija kolebatel'nyh sostojanij v sredah na osnove kondensirovannogo ugleroda i nanougleroda [Spectroscopy of vibrational states in condenced carbon and nanocarbon based media]. Abstract of a thesis for Doctorate degree in Physics and Mathematics. S. Petersburg, 2007. 40 p. (In Russian).

22. Kuzeev I.R., Popova S.V., Vasiliev A.N., Shemagonova E.V. Uglerod v strukture zheleznoj matricy i ego vlijanie na jekspluatacionnye svojstva konstrukcionnyh stalej [Carbon in the structure of iron matrix and its influence on the operational properties of structural steels]. Upravlenie kachestvom v neftegazovom dele [Quality Management in Oil and Gas Engineering]. 2010. № 1. p. 30-33. (In Russian).

\section{DeAr COlleagues!}

THE REFERENCE TO THIS PAPER HAS THE FOLLOWING CITATION FORMAT:

Kuzeev I.R. Identification of fullerenes in iron-carbon alloys structure. Nanotehnologii v stroitel'stve $=$ Nanotechnologies in Construction. 2017, Vol. 9, no. 6, pp. 151-163. DOI: dx.doi.org/10.15828/2075-8545-2017-9-6-151-163. (In Russian). 


\section{ИДЕНТИФИКАЦИИ ФУЛЛЕРЕНОВ В СТРУКТУРЕ ЖЕЛЕЗОУГЛЕРОДИСТЫХ СПЛАВОВ}

\section{АННОТАЦИЯ К СТАТЬЕ (АВТОРСКОе РЕЗЮме, РЕФЕРАТ):}

В строительной индустрии широко применяются стали различного назначения, например, в качестве армирующего материала в железобетонных конструкциях. В нефтегазовой отрасли используются стальные сооружения для хранения и транспортировки взрывоопасных токсичных сред. При этом случаются катастрофические разрушения, которые указывают на недостаточно глубокие знания о процессах, происходящих в конструкционных материалах в процессе их нагружения. Исследования последних лет указывают на то, что многие свойства сталей закладываются на наноуровне при кристаллизации из расплава и термической обработке. Обнаружение и идентификация различными методами фуллеренов С60 и С70, которые являются самостоятельными нанообъектами в структуре железа, требует изучения влияния этих объектов на формирование свойств сталей. Атомы железа могут выступать в качестве катализатора и, взаимодействуя с крупными ароматическими структурами или фрагментами графитовых плоскостей, формируют объемные структуры типа фуллеренов. При этом возможно и обратное явление: влияние образовавшихся нанообъектов на структурирование атомов железа, поскольку размер фуллеренов сопоставим с размером устойчивого зародыша кристаллической фазы железа. В работе обсуждается вопрос о механизмах образования фуллеренов в сталях и чугунах. Наиболее сложной проблемой в исследованиях является идентификация фуллеренов спектральными методами вследствие малого количества выделяемых молекул. Для повышения чувствительности метода ИК-спектрометрии фуллеренов предлагается использовать бромид калия. Высушенный и измельченный осадок, полученный в результате растворения матрицы железа в сталях, смешивается с бромидом калия, при этом смесь окрашивается в ярко оранжевый цвет. Это свидетельствует о присутствии бромистых фуллеренов и о наличии фуллеренов в исследуемых образцах. Показано, что предложенный алгоритм подготовки пробы существенно повышает чувствительность метода.

Ключевые слова: углерод, фуллерены, стали, ИК-спектрометрия, бромид калия, плавиковая кислота.

DOI: dx.doi.org/10.15828/2075-8545-2017-9-6-151-163 
МАШИНОЧИТАЕМАЯ ИНФОРМАЦИЯ о CC-ЛИЦЕНЗИИ В МЕТАДАННЫХ СТАТЬИ (НTML-КОД):

$<$ a rel="license" href="http://creativecommons.org/licenses/by/4.0/"><img alt="Лицензия Creative Commons" style="borderwidth:0" src="https://i.creativecommons.org/l/by/4.0/88x31.png" / ></a $><$ br $/>$ Произведение "<span xmlns:dct="http:// purl.org/dc/terms/" href="http://purl.org/dc/dcmitype/Text" property="dct:title" rel="dct:type">Идентификации фуллеренов в структуре железоуглеродистых сплавов </span>» созданное автором по имени <a xmlns:cc="http://creativecommons. $\mathrm{org} / \mathrm{ns} \#$ " href="Нанотехнологии в строительстве. - 2017. - Том 9, № 6. - C. 151-163. - DOI: dx.doi.org/10.15828/2075-85452017-9-6-151-163." property="cc:attributionName" rel="cc:attributionURL"> Кузеев И.P. $<$ а $>$, публикуется на условиях $<$ a rel="license" href="http://creativecommons.org/licenses/by/4.0/">лицензии Creative Commons «Attribution» ( ААтрибуция») 4.0 Всемирная $</ \mathrm{a}>$. $<\mathrm{br} />$ Основано на произведении с $<$ a xmlns:dct="http://purl.org/dc/terms/" href="http://nanobuild. $\mathrm{ru} / \mathrm{ru}$ _RU/nanobuild-6-2017/" rel="dct:source">http://nanobuild.ru/ru_RU/nanobuild-6-2017/</a>.<br />Разрешения, выходящие за рамки данной лицензии, могут быть доступны на странице $<$ a xmlns:cc="http://creativecommons.org/ns\#" href="kuzeev2002@mail.ru" rel="cc:morePermissions"> kuzeev2002@mail.ru</a $>$.

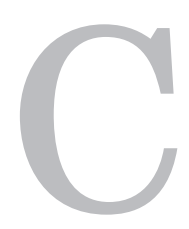

тали широко применяются в строительной индустрии в качестве армирующего материала в железобетонных конструкциях, для изготовления элементов трубопроводных коммуникаций, лифтов и т.д. Исследователи, которые работают над улучшением качества строительных материалов, а следовательно повышением безопасности эксплуатации различных объектов, склоняются к мнению, что многие важные свойства материалов формируются на наноуровне [1-3].

Кристаллизация железа из расплава, который образуется при реализации доменного процесса, предполагает участие углерода, поскольку и в чугунах, и в сталях углерод неизменно присутствует. Несмотря на то, что изучению сталей и чугунов посвящено множество исследований, роль углерода в формировании структуры и свойств железоуглеродистых сплавов требует дальнейшего изучения. На это указывается в работе [4]. Поскольку в коксе присутствуют различные соединения углерода, они генетически могут переходить в структуру железа и идентифицироваться как ароматические фрагменты, «взорванные глобулы», кольца и цепочки углеродных атомов, фрагменты графитовой структуры, например, коралловидной, хотя идентифицируются такие соединения, как графит и даже алмаз [5-12].

Идентифицируются также соединения железа с углеродом, которые известны под общим названием карбиды [5], например, обнаружена FeC-фаза [13]. Не всегда удается установить их химические формулы, поэтому они в совокупности обозначаются как є-карбиды [5]. Важную роль в создании структуры сталей отводится цементиту Fе3C, который входит в структуру перлита. Существуют многочисленные экспери- 
ментальные данные, свидетельствующие в пользу того, что цементит необходимо рассматривать как твердый раствор [14-17]. В работе [18] подробно рассмотрены вопросы, связанные с природой цементита. Отмечается, что в химической формуле цементита не соблюдается правило валентности; он нестабилен, вследствие чего до сих пор нет однозначного метода выделения цементита из стали. Наличие различных модификаций, которые получаются в результате термической обработки, также не подтверждает чисто химическую природу цементита, тем более, что отмечается реализация смешанной ковалентно-металлической связи, не свойственной химическому соединению [17]. Обнаружение и идентификация различными методами фуллеренов С60 и С70 в сталях и чугунах[18], с одной стороны, добавило некоторые сложности в оценке роли углерода в формировании структуры сталей и чугунов, с другой стороны, позволило с новой точки зрения взглянуть на происходящие при кристаллизации железа из расплава процессы.

Рассмотрим процесс кристаллизации из расплава. Особенности кристаллизации будут зависеть от направления и скорости съема тепла. Не вдаваясь в подробности, можно указать на то, что в большинстве случаев фронт кристаллизации будет иметь сферическую форму и распространяться будет от устойчивого зародыша кристаллической фазы. Учитывая стремление конфигурационной энтропии к минимуму, можно констатировать стремление фронта кристаллизации отталкивать примесные атомы, к которым следует отнести и атомы углерода, и оттеснять их к границам зерен. При увеличении скорости кристаллизации и изменении локальной температуры среды возможны случаи захвата примесей путем обтекания фронтом кристаллизации. Примеси могут образовывать структуры с выраженной поверхностью, при этом поверхность может служить местом образования дополнительных центров кристаллизации. В случае фуллеренов, например, они могут стать центром кристаллизации при фазовых переходах.

Обнаружение существования фуллеренов С60 и С70 в составе железоуглеродистой стали [18, 19] требует осмысления механизма их образования и определения места фуллеренов в структуре сталей и чугунов.

Атомы железа могут выступать в качестве катализатора [20] и, взаимодействуя с крупными ароматическими структурами или фрагментами графитовых плоскостей, формируют объемные структуры типа фуллеренов С60. При этом объемные структуры фуллеренов, связанные 
атомами железа, в различных плоскостях будут иметь характерную для решетки цементита ковалентно-металлическую связь.

Исследование фуллеренов в сталях и чугунах является трудоемким процессом, требует растворения матрицы железа, например, в плавиковой кислоте, получения осадка и экстрагирования фуллеренов. Далее следует подготовка проб для исследования с применением ИКспектрометрии. Этот процесс был использован в исследованиях [18], но требует совершенствования.

Поскольку фуллерены обладают высокой симметрией, спектр инфракрасного поглощения достаточно беден, что упрощает их идентификацию. Экстракцию фуллеренов проводят с помощью неполярного растворителя, например, толуолом с дальнейшим концентрированием вещества жидкостной хроматографией. Однако количество выделенного вещества может оказаться вне зоны чувствительности приборов.

Недостатком существующих методов идентификации фруллеренов является также то, что присутствующие в образце эндоэдральные металлофуллерены и фторпроизводные фуллеренов полимеризуются и существенно снижают эффективность экстракции из твердой пробы. В связи с этим возникают трудности при количественном выделении фуллеренов, которые необходимо преодолевать для повышения чувствительности метода анализа спектров.

Предлагаемый метод основан на эффекте интенсивного окрашивания смеси фуллеренов и бромида калия. Возникающий коллоидный раствор в водной среде дает ярко оранжевую окраску. Интенсивность окраски изменяется в зависимости от содержания фуллеренов и позволяет сравнивать получаемые пробы на их содержание.

Поскольку известно, что соли переходных металлов катализируют реакции взаимодействия галогенов с фуллеренами, то образование бромистых фуллеренов в составе железоуглеродистого сплава должно проходить более интенсивно.

При обработке НF образцов металла образуется растворимый в воде осадок фрторида железа желто-зеленого цвета и твердые включения углерода, который можно идентифицировать как фуллерены или графит.

Высушенный и измельченный осадок смешивается с бромидом калия, при этом смесь окрашивается в ярко оранжевый цвет. Это свидетельствует о присутствии бромистых фуллеренов и о наличии фуллеренов в исследуемых образцах. 
a)

б)

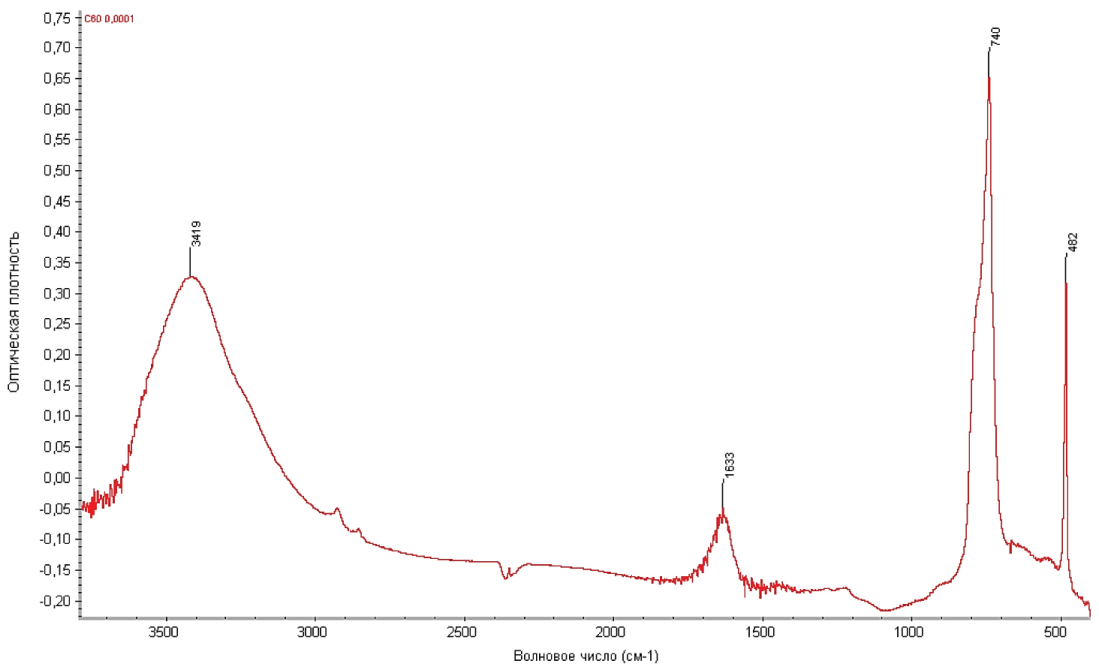

Puc. 1. Инфракрасные спектры бромистых производных фуллеренов: а) $\mathrm{C} 60$; б) $\mathrm{C} 70$;

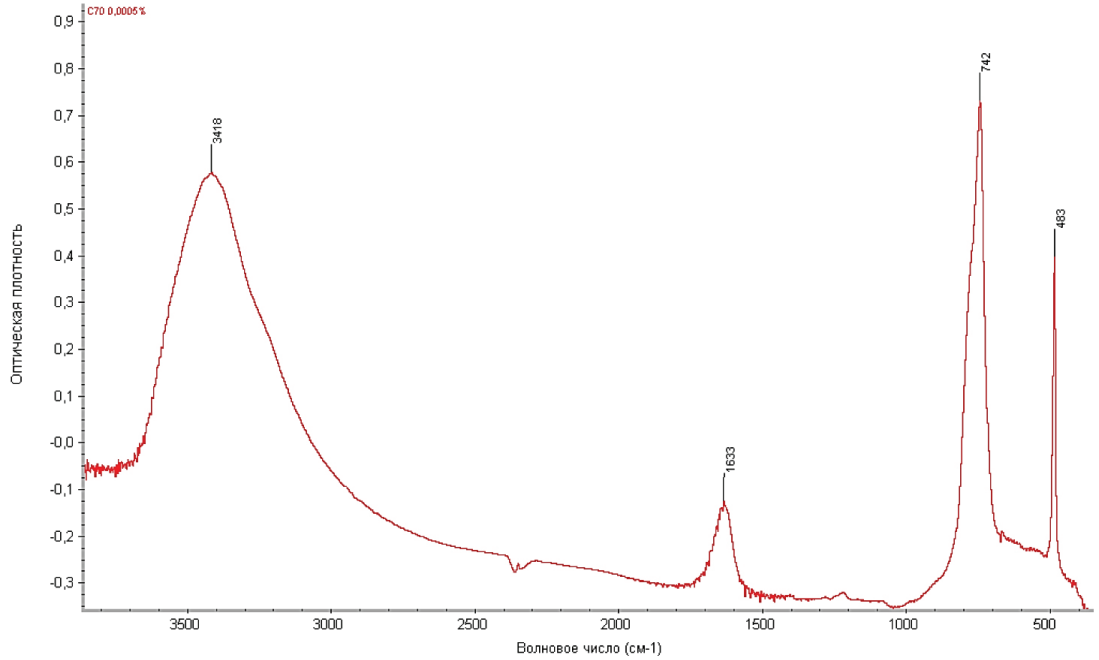

6) в) $\mathrm{C} 60+\mathrm{C} 70$

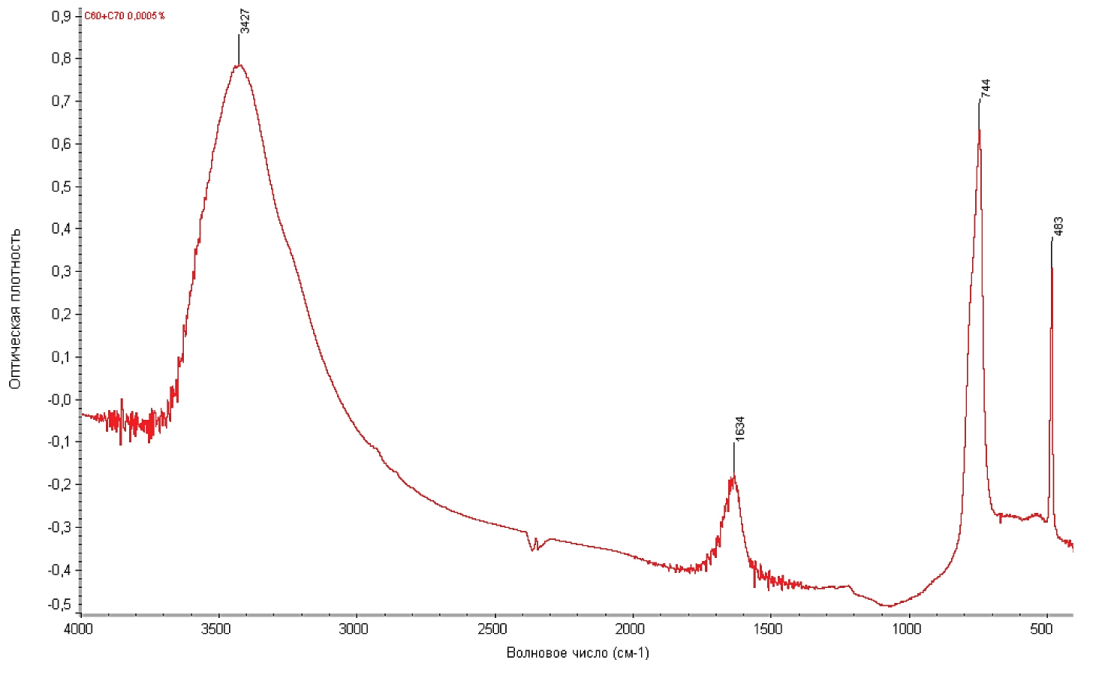


Образование бромистых фуллеренов резко повышает чувствительность спектрального анализа вследствие изменения симметрии фуллереновой молекулы и ее массы.

Для калибровки прибора готовились эталонные образцы фуллеренов чистотой $99,7 \%$, которые провзаимодействовали с бромидом калия.

Спектры бром производных фуллеренов С60 и С70 показаны на рис. 1.

a)

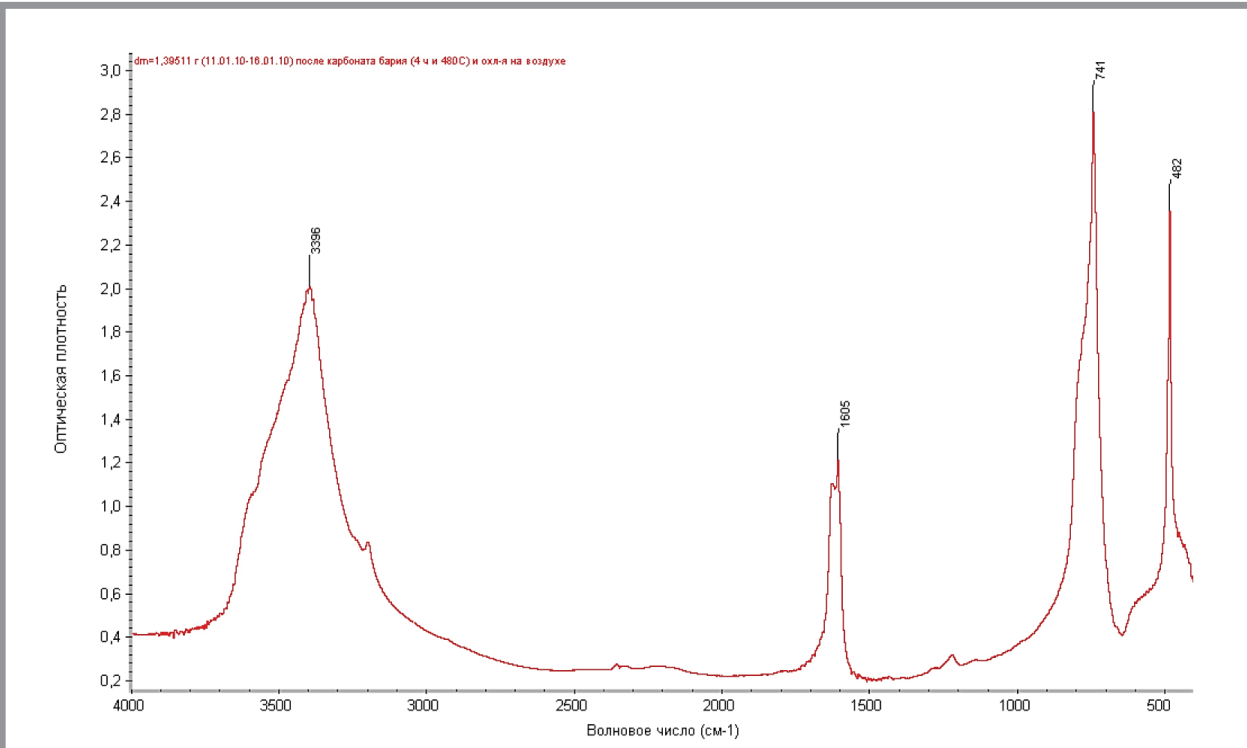

б)

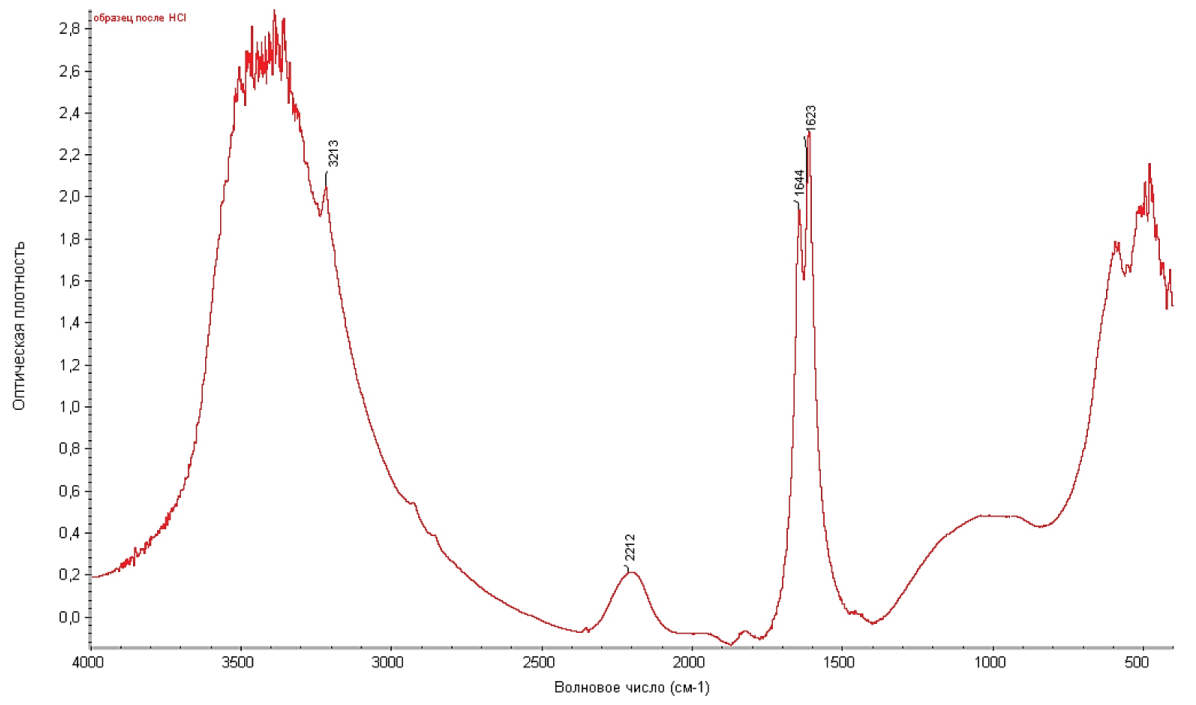

Рис. 2. ИК-спектры металлофуллеренового поверхностного слоя: а) после воздействия $\mathrm{HF}$; б) после воздействия $\mathrm{HCl}$ 
Анализ спектров показал, что имеют место интенсивные пики на частотах 482 и $742 \mathrm{~cm}^{-1}$. В низкочастотной области спектра молекулы C60 и C70 возникают пики вследствие колебаний совпадающих по частотным характеристикам для обоих фуллеренов. Проявляется широкий пик гидроксильной группы (частоты $3400-3420 \mathrm{~cm}^{-1}$ ), связанный с адсорбированием влаги из воздуха, и пик на частоте $1632 \mathrm{~cm}^{-1}$, указывающий на взаимодействие фуллерена с кислородом [21]. Можно также отметить, что сравнение спектров указывает на большую реакционную способность бромистых фуллеренов по отношению к кислороду, чем чистых фуллеренов.

Соляная кислота разрушает фуллерены из-за высокой реакционной способности образующихся хлорпроизводных фуллеренов с кислородом воздуха. На рис. 2 представлены спектры металлофуллеренового поверхностного слоя стали 20 после воздействия плавиковой и соляной кислот.

Исследования показали, что бромистые фуллерены в отсутствии атомов железа распадаются, а атомы железа стабилизируют эти соединения.

Таким образом, разработан алгоритм идентификации фуллеренов в структуре сталей и чугунов, который включает растворение металлической матрицы плавиковой кислотой, тщательное фильтрование осадка, сушку фильтрата, подготовку мелкодисперсного порошка [22], прессование таблеток с бромидом калия для получения тонкого прозрачного слоя, снятие спектров в области частот $400-4000 \mathrm{~cm}^{-1}$. При этом чувствительность метода существенно увеличивается.

Автор выражает благодарность к.т.н. Поповой С.В. за помощь при проведении экспериментов.

Исследования проводятся в Уфимском государственном нефтяном техническом университете в рамках реализации инициативного научного проекта фундаментального характера по государственному заданию образовательным учреждениям высшего образования на 2017-2019 г2. (№ 9.7294.2017/8.9 от 31.01.2017) при содействии Межвузовского центра коллективного пользования «Региональный научно-производственный комплекс «Недра»». 


\section{Библиографический список:}

1. Власов B.A. Изобретения в области нанотехнологий обеспечивают повышение прочности и ресурса конструкций из металлических, композиционных полимерных и металлополимерных материалов // Нанотехнологии в строительстве. - 2014.- Т. 6., № 1. - С. 68-90.

2. Власов B.A. Изобретения в области нанотехнологий существенно улучшают эксплуатационные свойства бетонов, полимеров, металлов и других материалов // Нанотехнологии в строительстве. - 2014. - Т. 6., № 3. - С. 77-95.

3. Кондаков А.И. Модификация матрицы строительного композита функционализированными углеродными нанотрубками / А.И. Кондаков, З.А. Михалева, А.Г. Ткачёв, А.И. Попов, С.Ю. Горский // Нанотехнологии в строительстве. 2014.- Т. 6., № 4. - С. 31-44.

4. Закирничная M.M. Образование фуллеренов в процессе диффузии углерода в структуру стали / М.М. Закирничная, И.Р. Кузеев, О.И. Ткаченко // Известия высших учебных заведений. Нефть и газ. - 2012. - № 2. - С. 112-119.

5. Гуляев А.П. Металловедение. - М.: Металлургия, 1986. - 544 с.

6. Губенко С.И. К вопросу о синтезе алмаза // Материаловедение и термическая обработка металлов. - 1994. - № 3. - С. 37.

7. Жуков A.A. Об образовании компактного графита в чугуне / А.А. Жуков, Р.Л. Снежной, С.В. Давыдов // Материаловедение и термическая обработка металлов. - 1981. - № 9. - С. 21.

8. Килстач Г.М. Об образовании карбина в $\mathrm{Fe}-\mathrm{C}$ сплавах / Г.М. Кимстач, А.А. Уртаев, Т.Д. Молодцова // Материаловедение и термическая обработка металлов. - 1988. - № 4. - С. 9-12.

9. Килстач Г.M. О существовании карбина в структуре аустенитного чугуна / Г.М. Кимстач, А.А. Уртаев, Т.Д. Молодцова // Материаловедение и термическая обработка металлов. - 1991. - № 2. - С. 17-18.

10. Ж Жуков A.A. О формах существования углерода в чугунах // Материаловедение и термическая обработка металлов. - 1992. - № 11. - С. 34.

11. Zhukov A.A. Soviet research work on the liquid state on cast iron / A.A. Zhukov, R.L. Snezhnoy, N.G. Girshovitch // AFS International Cast Metals Journal. 1976. - № 1. - P. 11-16.

12. Zhukov A.A. New findings in carbon chemistry and their relation to cast iron / Zhukov A.A., Ramachandra Rao P. // Indian Foundry Journal. - 1994. - № 6. P. 13-18.

13. Гветадзе Р.Г. Особенности формирования структуры высокопрочных деформируемых чугунов / Р.Г. Гветадзе, Н.3. Хидашели, В.Г. Черный, Г.Н. Гогесашвили, 3.В. Свистунова // Литейное производство. - 1990. - № 3. - С. 708.

14. Lipson H. The crystal structure of cementite Fe2C / H. Lipson, N.J. Petch // Iron and Steel Institute. - Vol. 142. - № 1. - P. 95-106. 
15. Гаврилюк В.Г. Распределение углерода в стали. - Киев: Наукова думка, 1987. 207 c.

16. Рахланов Н.Я. Тепловое расширение цементита заэвтектоидного железоуглеродистого сплава / Н.Я. Рахманов, А.Ф. Сиренко, С.А. Баларев // Материаловедение и термическая обработка металлов. - 1997. - № 1. - С. 6-11.

17. Арзаласов Б.Н. Материаловедение. - М.: Машиностроение, 1986. - 394 с.

18. Закирничная M.M. Образование фуллеренов в углеродистых сталях и чугунах при кристаллизации и термических воздействиях. - Уфа: «Гилем», 2002. - 180 с.

19. Кузеев И.Р. Исследование углеродных форм в железоуглеродистых сплавах / И.Р. Кузеев, С.В. Попова, Ю.Н. Савичева // Геология. Известия Отделения наук о Земле и природных ресурсах АН РБ. - 2009. - № 14. - С. 135-136.

20. Долрачев Г.A. Роль углерода и металла в самоорганизации системы железо - углерод при различном содержании компонентов / Г.А. Домрачев, А.И. Лазарев, Б.С. Каверин, А.Н. Егорочкин, А.М. Объедков, Е.Г. Домрачева, Л.Г. Домрачева, Г.В. Марки, Nava Е. Нuipe, А.А. Сорокин, О.Н. Суворова, В.Л. Карнацевич, А.И. Кириллов, А.А. Закуражнов // Физика твердого тела. - 2004. - Т. 46. - Вып. 10. - С. 1901-1915.

21. Бехтерев А.Н. Спектроскопия колебательных состояний в средах на основе конденсированного углерода и наноуглерода // Автореферат диссертации на соискание ученой степени доктора физ-мат. наук. - С. Петербург. - 2007. - 40 с.

22. Кузеев И.Р. Углерод в структуре железной матрицы и его влияние на эксплуатационные свойства конструкционных сталей / И.Р. Кузеев, С.В. Попова, А.Н. Васильев, Е.В. Шемагонова // Управление качеством в нефтегазовом деле. - 2010. - № 1 - С. 30-33.

\section{УВАЖАЕМЫЕ КОЛЛЕГИ!}

ПРИ ИСПОЛЬЗОВАНИИ МАТЕРИАЛА ДАННОЙ СТАТЬИ

ПРОСИМ ДЕЛАТЬ БИБЛИОГРАФИЧЕСКУЮ ССЫЛКУ НА НЕЁ:

Кузеев И.Р. Идентификации фуллеренов в структуре железоуглеродистых сплавов // Нанотехнологии в строительстве. - 2017. - Том 9, № 6. - C. 151-163. - DOI: dx.doi. org/10.15828/2075-8545-2017-9-6-151-163.

\section{Dear Colleagues!}

THE REFERENCE TO THIS PAPER HAS THE FOLLOWING CITATION FORMAT:

Kuzeev I.R. Identification of fullerenes in iron-carbon alloys structure. Nanotehnologii v stroitel'stve $=$ Nanotechnologies in Construction. 2017, Vol. 9, no. 6, pp. 151-163. DOI: dx.doi.org/10.15828/2075-8545-2017-9-6-151-163. (In Russian). 